\title{
How to Write An Effective Research Proposal for Higher Degree Research in Higher Education: Lessons from Practice
}

\author{
Dr Charles Kivunja ${ }^{1}(\mathrm{PhD})$ \\ ${ }^{1}$ Senior Lecturer in Pedagogy and Educational Leadership, Researcher: Embedding Social Media Technologies in \\ Pedagogy, Manager Leximancer Qualitative Software, School of Education, The University of New England, \\ Armidale, 2351, New South Wales, Australia \\ Correspondence: Dr Charles Kivunja, Senior Lecturer in Pedagogy and Educational Leadership, School of Education, \\ The University of New England, Armidale, 2351, NSW, Australia
}

Received: March 6, 2016

Accepted: March 20, 2016

Online Published: March 22, 2016

doi:10.5430/ijhe.v5n2p163

URL: http://dx.doi.org/10.5430/ijhe.v5n2p163

\begin{abstract}
Admission into a higher degree research program or confirmation of candidature into such a program of most universities often requires the applicant to submit a research proposal. This is a very important document which not only articulates the research topic and research question, but also explains the research design which outlines how the proposed research will be carried out. The significance of the research proposal is highlighted by the fact that failure to write a good research proposal may mean failure to be admitted into a higher degree research program, or failure to be confirmed as a continuing doctoral candidate. In spite of such significance, however, my experience when supervising many higher degree research students is that many of them struggle to write a good research proposal. One of the contributing factors to this is the apparent void that exists in research methods textbooks on exactly what a research proposal is and how it should be written. This paper aims to help fill that void by articulating a detailed structure of a research proposal that could be used as part of the application to gain admission into a higher degree research program of any good university or for confirmation of candidature in such a research study program. The paper draws on the expertise accumulated on this topic as a result of many decades of writing research proposals for higher degree research projects, conducting many higher degree research studies successfully in several universities in Australia and other countries, teaching research methods to higher degree research students and supervising many successful masters and doctoral theses. The paper concludes, that while there is no 'one-size-fits-all' research proposal, a careful design of a higher degree research proposal along the structure discussed in this paper should improve one's chances of success greatly.
\end{abstract}

Keywords: Higher degree research, Research proposal, Thesis plan, Research methods in education

\section{Introduction}

\subsection{Personal Reflections on Conducting Higher Degree Research}

Most scholarly papers that contain a reflective section usually place it towards the end of the paper. However, I have decided to start with it here so as to give the reader, right at the start, an understanding of how my personal involvement in higher degree research (HDR) has shaped my world view about how an effective research proposal for the award of a higher degree should be written. By higher degree I refer to second tier and third tier degrees. In this classification, bachelors' degrees are in the first tier, masters' degrees belong to the second tier and doctoral degrees are located in the third tier. These classifications might differ across different educational jurisdictions and institutions, but in Australian universities these classifications are the norm, and in education in particular, the doctoral classification tier comprises the EdD (Doctor of Education) and the PhD (Doctor of Philosophy).

The views I share in this paper are intended to help readers understand how to write a good HDR proposal. They are informed by many years of personal engagement with HDR either as a HDR student or a HDR Supervisor. As a student at the University of Nairobi, my first HDR proposal was for a Master of Science in Agricultural Economics degree. The research proposal was for the HDR project entitled the Economics of Cattle and Beef Marketing in Kenya. The central focus of the thesis was an investigation into the factors that influenced the demand and supply for beef throughout Kenya. A major part of the thesis was the estimation of what in economics and econometrics is called the income elasticity of demand (Draper \& Smith, 1966) for Kenyan beef. This estimation answered the 
research question, how does a given percentage change in the prices of beef, other meats, or in peoples' incomes, and in combinations of these factors, affect peoples' demand for beef? You can easily see that this was a HDR that required the use of quantitative research methods. It was therefore located in what is known as the positivist paradigm (Keeves, 1997). Successful completion of that HDR project led to the award of my first Masters Degree and to the publication of my first book entitled The Economics of Cattle and Beef Marketing in Kenya (Kivunja, 1978). Following that graduation I worked as an Agricultural Economist on a United Nations Research Project at Ibadan, in Nigeria, where my research involved interviewing farmers to understand their farming practices so we could improve their crop yields. Because that research used interviews, it gathered qualitative data and it was therefore located in what is known as the interpretivist paradigm (Denzin \& Lincoln, 2000), or constructivist paradigm (Guba \& Lincoln, 1989). The analysis of data involved interview transcripts, which were qualitative data (Merriam, 2001), but also numerical data of farm management practices such as acreages, seeding rates, fertilization rates, pesticide application, frequency of weeding, irrigation, crop yields, and market prices. As a result the data analysis methods were both qualitative and quantitative, and hence, characterized as mixed research methods (Cresswell \& Plano, 2007). My second HDR was at the University of Sydney, where my Master of Agricultural Economics degree project used data gathered from the Nigerian farms described above to develop optimal development paths for the growth of small farms in Nigeria. The results which were published in a thesis entitled, The economics of the development of small farms in Africa, (Kivunja, 1984) were obtained using recursive linear programming algorithms (Beneke \& Winterboer, 1973), which enabled me to estimate the optimal growth paths for the farms studied, so they could expand from being small peasant farms, to relatively large farm firms (Kivunja, 1984, p. 198). That HDR was therefore primarily quantitative in its methods of data analysis (Render \& Stair, 1994) and therefore located in the positivist paradigm (Neurath, 1973). Two other HDR projects conducted at the University of Western Sydney both involved research proposals that led to projects that used qualitative research methods. The HDR for the Master of Educational Leadership investigated the literature on leadership and leadership's impact on learning and teaching (Kivunja, 2001). The HDR for my PhD in Pedagogy developed The Dynamics Paradigm for Analyzing the Structural and Cultural Dynamics in Multiple Campus Colleges in New South Wales (Kivunja, 2006; Kivunja \& Power, 2006) and was based on large amounts of interview data gathered from 14 multi-campus colleges in the public schools system of NSW. These personal academic pursuits have been followed by many years of supervising many HDR students who have written research proposals for their HDR projects at university level. It is this personal and professional immersion in HDR projects over many years that has given me the understanding that it is not easy to write a good research proposal for a HDR project, and that in fact many students struggle to complete this task. This understanding, I believe informs my understanding of how to write a good research proposal for a HDR project, especially in higher education, which I believe when shared through this highly ranked international journal, could help people intending to undertake HDR at either masters or doctoral level, write an effective research proposal that would facilitate their admission into any university of their choice, and subsequently enable them to conduct a successful research project leading to the award of a higher degree. The aim of this paper, therefore, is to help the reader understand four things about research proposals for HDR. Firstly, what do we mean by a HDR proposal? Secondly, what purposes does it serve the student and the university? Thirdly, what does a good HDR research proposal look like? And finally, what precautionary measures should you take to enhance your chances of writing a research proposal that will be accepted for a HDR project leading to the fulfillment for the award of a degree at masters or doctoral level?

\section{What is a Higher Degree Research Proposal?}

A higher degree research proposal (RP) is a document that provides information to others about the project you propose to undertake as part of your study for a higher degree (Dunleavy, 2003). Many universities require all applicants for admission into Higher Degree Research (e.g: Masters, EdD and PhD) to include a RP with their application. This is an abridged version and is expected to be between $3-5$ pages. Following admission, the student is usually put on a probationary period of up to six months, during which s/he works on his or her initial RP and develops it into a detailed RP which they then present to a panel of experts, which uses that RP as the basis for the confirmation of candidature (COC) into a higher degree. This is usually a very comprehensive document and may vary in length between $30-50$ pages. So you can see there is great variance in length but I hope you can also see from this description of the RP, that it is one of the key documents that support your application for admission, and also your most important document to secure and confirm your candidature in a HDR program. It is therefore a very important document, and needs to be approached very carefully. If a RP is rejected, your admission into a HDR program cannot proceed.

As said earlier, the initial RP is developed on your identified topic and submitted as part of your application for admission. After admission, you undertake significant developments of your RP and when it has been developed to the 
satisfaction of your supervisors, an appointment is be made for you to present it to the Panel of Experts in your area of proposed research. This is done at what is called the COC - Seminar. The size of the panel varies across faculties and universities but it normally consists of at least three experts plus your supervisors. Your supervisors select the panel but the Higher Degrees Research Committee of the university approves it. Successful completion of the COC ends your probation and marks the beginning of your full candidature in any HDR or doctoral research proper. The COC is a very important step because everything else that you do during your candidature depends on it. It is the road map for your HDR and once it is agreed upon you are held to it and you hold the university to it. So, let's have a good look at the different purposes that the RP serves

\section{What Purposes Does the Research Proposal Serve?}

In a nutshell, the RP informs others about exactly what you want to do your research on, why it is important to do it, how you will do it, any ethical issues you might need to address, the resources you will need, how long it will take you, and how you will finance it. Its specific purposes are:

- To meet the requirements for your admission into a HDR program

- To have your candidature confirmed for HDR study

- To articulate your research topic

- To define your research question and explain how you will go about answering it

- To highlight the importance of your proposed research and what contribution it will make to the discipline

- To explain how it fits into what is already known and how it adds to it

- To explain your entire research plan and how you will implement it

- To provide an outline for your dissertation

- To gain attention and interest of academics who might be your supervisors.

\section{What Does a Good HDR Research Proposal Look Like?}

There is no one way a RP must be structured. However, the RPs that usually succeed first time at the COC follow a structure similar to the one I propose below. You are of course welcome to vary it according to your understanding of what you want to do, or what your university prescribes.

\subsection{Introduction}

This should be a very brief, and clear statement of what your RP is about, the general area in which it is located, the specific area of your interest, why that area is your focus (e.g. a gap in knowledge), the research question you will ask to help fill that gap, why it is important to fill that gap, the aims you hope to achieve, and a statement of your tentative argument (the thesis), about filling that gap. This introduction should serve as a comprehensive summary of your RP, which is so worded that it would make sense to a reader who is not a specialist in your proposed field of research.

\subsection{Identification and Articulation of a Researchable Topic}

A good way to start thinking about how you will go about identifying your research topic is to remember what research is. Re-search, simply means, looking and looking again; searching and searching again (Burns, 2000). So, now you ask yourself, what sorts of things, objects, ideas, or people might I want to look at again and again? The answer is inevitably going to be that it will be objects, ideas or people that interest you. Objects, ideas or people, you want to be associated with. Therefore, the first step in identifying your research topic is to ask yourself what interests you about what you might research into. The best way to do this is to sit back, relax, and brainstorm yourself about what interests you in education such that you might be interested in conducting an investigation into it?

What interests you should be something relevant to your life, your career or profession, what you do or your relationships with people, particularly those you can impact, and those whose actions or decisions could have an impact on you or on others that interest you. For example, in education what interests you could be, the impact of public tests on learning and teaching. An example of these from Australian educational contexts is the National Assessment Program in Literacy and Numeracy usually abbreviated simply as NAPLAN, which is administered to students in years 3, 5, 7 and 9. Other areas of interest in education could be policies of the Institute of Teachers, school fees paid by students enrolled at your school, professional development opportunities available at your school, the role of the principal in creating structures and cultures at your school that affect teaching and learning (Kivunja, 2006), the role of sports in child development, teaching children in mixed or streamed classes, how digital pedagogy improves pre-service higher education (Kivunja, 2013), homework, how embedding social media in teaching could 
improve learning, teaching and assessment (Kivunja, 2015a), dealing with children with disabilities in main stream, teaching children of special abilities, how the use of the Super 4Cs of the $21^{\text {st }}$ Century improves learning in a primary classroom (Kivunja, 2015b), sex education at your school, the effect of domestic abuse on children's learning, how to make assessment attractive to students (Kivunja, 20015c), teaching strategies you can use to become the best teacher you can be (Kivunja, 2015d). The topic you identify is articulated as the title for your RP and so you should make sure it describes the content and direction of your RP using key words, which attract the attention of potential supervisors for your HDR.

\subsection{Description of Background, Context and Statement of the Problem to be Investigated}

Here you explain your answers to these questions:

- What is already known about your topic?

- What is missing?

- What more is needed?

- Is there a problem?

- Why does this problem exist?

4.4 Statement of the Significance of the Study

To be able to state the significance of the study you propose to undertake, you should ask yourself the following questions, and use the answers to explain the importance of your research and to justify why it is worth doing:

- Why is it important that the problem I have identified be investigated?

- What contribution will the investigation make? To whom? How? Why?

- How original is this contribution to the discipline?

- Why is this research worth pursuing?

- What is the theoretical and practical importance of the outcomes of my research?

- Which research issues are evident in the relevant literature?

- How will my research address these issues?

- What are the expected outcomes and why are they important?

- Who will benefit? How? Why?

- How does my research link with what has been done in this field?

- How can my research complement what is happening in this area?

- Is there some way I can use my research to extend an existing model or way of thinking or analysis?

- What really justifies my research?

4.5 Scope, Aims and Objectives of the Study

It is very easy for students and early career researchers to be over ambitious regarding how much they want to achieve as the outcome of their research. It is important for you to recognize that your research is not intended to provide solutions to every problem you can think of in education, or in your specific subject or field. Your RP is being submitted for an academic purpose, namely to get you into a university or help you to earn a degree. So, you should state its scope, aims and objectives that are realistically achievable (Burns, 2000). State exactly what you want to learn as a result of conducting your proposed research. These questions should help you complete this part of your RP:

- What do I intend to prove or disprove?

- What shall I understand more deeply, analyze, evaluate or create?

- What shall I test and demonstrate?

- Is there a hierarchical list of aims I seek to achieve?

4.6 Review of Literature Informing the Study

The literature review is intended to demonstrate to whoever will read your RP that you have a good grasp on the literature in the field of your proposed research, that you can use it well in your research, and you can contribute to it 
(Cohen \& Manion, 1995). It offers greater contextualization of your study based on what others have done in your area of proposed research. Again, I find that if students ask themselves the following questions; the answers help them to carry out a comprehensive literature review that satisfies supervisors and examiners.

- How does what has been done link with what I want to do?

- What do leaders in the field say about the problem I propose to investigate?

- Which are the major issues on this topic or generally in this area or field?

- Which gaps does the literature highlight?

- What research questions does the literature inform?

- Which hypotheses can I formulate based on this literature?

- Does the literature contain new terms, ideas, concepts or themes that need to be explained or unpacked?

- Does the literature contain theoretical perspectives that inform how I should conduct my proposed research?

- Does the literature suggest an appropriate paradigm in which to locate my RP?

- Does the literature shed light on research methods that have been used effectively in research like mine?

- What debates are going on or have gone in this area?

- What can I contribute to those debates?

- Is there a thesis I can review to see how it is structured and the type of literature that it reviewed?

\subsection{Research Question/s to be Investigated}

A good starting point in formulating the research question (RQ) for your RP is to ask the simple question: What is a research question? In HDR research proposals (See for example, Schwab, 2005), a RQ is not just a question about your research. It has a special meaning and carries a lot of weight as you can see in this definition, and explanation. A research question is that cardinal question which centers our research efforts and focuses them on mounting a scholarly argument that helps us to solve the problem identified as important for our research (Cohen \& Maldonado, 2007). As such, your RQ should be a concise, clearly articulated, complex but an arguable question, which is the central pillar around which you centre your entire research project. So, the RQ is the question, which indicates to you, and to your potential supervisors, and examiners of your thesis what you wanted to know. This means that the RQ is an unambiguous statement that clearly articulates the phenomenon you plan to investigate. It guides and centers your research project. It should therefore be clear and focused, as well as synthesize what you want to research into, and to present your unique argument on. I say an 'argument' because that is exactly what a thesis is. It is a scholarly argument that you create about a particular problem. Most arguments are not represented or won by Yes or No answers. Neither should your RQ be one that can be answered with just Yes or No responses. Most Yes or No answers do not explain complex ideas, concepts, or themes. Yet for a research proposal for a HDR project to succeed, it must be judged as having the potential to contribute to an understanding of a relatively complex issue or problem.

Thus, the RQs are the questions whose answers will enable you to make a contribution to knowledge. Evidence of a significant contribution to knowledge is a primary requirement of all doctoral theses. Since this is what you get awarded a doctoral degree for, you need to give it your best shot. So the research question/s need to be very carefully thought about and thoughtfully framed. They need to be important, open-ended, requiring complex answers, but answers you can provide, as a result of your research. The RQs usually comprise the main research question that is often referred to as the overarching research question, followed by a few subsidiary research questions that are very specific. I recommend a simple 1 and 5 rule for my students. That is, have one overarching question, followed by no more than five subsidiary questions.

\subsection{Theoretical Framework}

The theoretical framework (TF) articulates the theoretical views expressed by leaders in the field into which you plan to research (Scott \& Usher, 2004). Ideally, the TF should emerge from your literature review. A good TF usually contains a model that you will use to analyze and make sense of your data. Students will often say, my research is on a new topic and there is no theory already developed in this area. This is usually an indication that their literature review has either been superficial, or not broad and deep enough, or they are unable to connect the dots in the literature that would enable them to come up with a TF. I argue that trying to conduct a HDR project without grounding it in a well-articulated TF is like trying to erect a building on shifting sand. Such a building would have no foundation. The $\mathrm{TF}$ will be the foundation for all your sense making of the meaning contained in the findings contained in your data. If 
you describe, explain or discuss your findings without referring to good theory, you are probably engaged in non-scholarly talk (and perhaps street talk), which won't gain you into a postgraduate program in a good university and certainly not earn you a higher degree. If, as you prepare your RP, you haven't found one (i.e. a TF) in your literature, it is because you haven't looked hard enough. Keep looking, and you will eventually find one. The TF is extremely important because it serves as the essential coat hanger for your data analysis, interpretation of results, and discussion of your findings. So, as you look for one, ask yourself the following questions:

- Is there a theory that will help me to make sense of the meaning of the data I will gather to answer the RQs?

- What do giants in the field of my proposed research say about the problem I want to investigate, from conceptual dimensions?

- How can I modify what they have said, so as to come up with my own theorization about the meaning contained in my research data?

\subsection{Methodology}

In HDR terminology, methodology is the way the entire research project is designed and conducted (Scott \& Usher, 1996). It addresses the question: How will you approach the research, design and conduct it so as to be able to answer the RQs? Unpacking this global question, leads to asking the following specific questions:

- In which Paradigm will you locate your research? Will it the positivist, interpretivist, critical or the pragmatic? A good discussion of the different paradigms is available in good research methods textbooks and publications such as Guba (1992), Patton (1988) Burns (2000), Cohen and Manion (1995).

- Why will this be the appropriate paradigm for my research?

- Which Research Design will you follow? For example, will it be case study or survey, or phenomenology, or ethnography, or hermeneutics, or narrative inquiry, or grounded theory? (See for example, Glesne, 1998; Bell,1987; Glaser \& Strauss, 1999, and Lancy, (1993).

- Why will this be the optimal design for my research?

- Which Research Method/s will I use? For example, will I use quantitative methods, or qualitative or mixed methods? (See for example, Le Compte, Milroy \& Preissle,(eds). (1988).

- Why will this be the appropriate method for my research?

- Who will be the Participants? For example, will you hold individual interviews, group interviews or focus groups? (See for example, Cooksey \& MacDonald, 2011).

- How will I select them? How many? Why?

- How will I Gather the Data?

- Which Instruments will I use? For example, will my data gathering instruments include questionnaires or online or mail surveys?

- Which Procedures shall I follow? Why?

- Will travel or fieldwork be involved?

- How will I Analyze the Data? For example, will I undertake thematic collation, relational analysis, axial coding, statistical algorithmic, or statistical equations?

- Which Tools, Software, or data management procedures shall I use?

- Methodological Limitations. Ask yourself, are there any? How will I work around them so they don't impede my proposed research?

- Which are the Ethical considerations? Ask yourself, are there any ethical issues? If so, how will I address them?

Every study that involves research on humans needs to be cleared by the Human Research Ethics Committee (HREC) of your university or institution in which your research will be based. You need to access the HREC website of the relevant institution and see that you are familiar with the policies that apply to your RP. You should discuss this with your supervisors and you will need to seek approval from the HREC. Most of the points highlighted in the above bulleted points are discussed at length in good research methods texts such as Cohen and Maldonado (2007, Burns (2000), and Denzin and Lincoln (2000). 


\subsection{Research Plan and Time-frame}

This should present a schedule of all activities showing the sequence of your research phases and when you propose to start and complete each. Obviously the timeline is only an expectation, but it is a very important part of the RP because it shows readers of your RP that you have thought about the feasibility of your research project. To achieve this aim, you should tabulate data which make it very clear that you have a reasonable understanding of the time that you will need for each major part or step of your research study. One possible good way to design such a Table is to tabulate the different steps of your research proposal and show what you will do in each step, when, and how much time you plan to spend on each. Such a schedule could be designed as illustrated in Table 1.

Table 1. Research Time-frame for my HDR Project

\begin{tabular}{llll}
\hline $\begin{array}{l}\text { Step } \\
\text { ID }\end{array}$ & Research step & $\begin{array}{l}\text { What } \begin{array}{c}\text { I } \\
\text { Briefly indicate } \\
\text { you will do }\end{array} \\
\text { exactly }\end{array}$ & $\begin{array}{r}\text { That } \\
\text { what }\end{array}$ \\
\hline $\mathbf{1}$ & Introduction & & Jan \\
$\mathbf{2}$ & Defining Research Topic & Jan and Feb \\
$\mathbf{3}$ & Background, Context and Problem Articulation & Feb \\
$\mathbf{4}$ & Significance of the study & Feb \\
$\mathbf{5}$ & Scope, aims and objectives & Feb \\
$\mathbf{6}$ & Literature Review & March \\
$\mathbf{7}$ & Research Question & Feb and March \\
$\mathbf{8}$ & Theoretical Framework & April \\
$\mathbf{9}$ & Methodology & April \\
$\mathbf{1 0}$ & Research Plan and Time-frame & May \\
$\mathbf{1 1}$ & Budget & May \\
$\mathbf{1 2}$ & Thesis Plan & May \\
$\mathbf{1 3}$ & References & Jan - May \\
\hline
\end{tabular}

As you can see in the Table, developing a good research proposal is likely to take you about six months. In many universities, this is the period allowed for your probationary doctoral candidature. After the six months, you are required to present your detailed RP which is used for the confirmation of your candidature (or not). So, as you look at the structure of this Table, consider carefully how much time your university allows you to prepare your final RP. Each of the steps of the RP requires a reasonable amount of time, and setting them out as illustrated above should help to ask yourself the following questions:

- How much time does the university allow me to develop my RP?

- Realistically, given my personal circumstances (work, family, travel, health, relationships, other), when can I start and when will I finish?

- What other deadlines do I have to meet during this period?

- Which are the different stages of my RP development that I will need to develop?

- Have I allowed for time to discuss the development of my RP with my supervisors?

- Have I allowed realistic timing for each step?

- How will I tell that I am making good progress?

\subsection{Budget and Other Resources Required}

This is where you prioritize the different activities of your research project and allocate the amount of money available to you to each, accordingly. You need to ask yourself the following questions:

- Will I need to travel to meet with my supervisors during my RP preparation?

- Will I be staying overnight and therefore needing hotel accommodation?

- Will I need to purchase any research materials, such as published reports ? 
- Will I need a new computer or new software?

- Will there be printing costs?

- What other costs involved?

- Have I made arrangements to meet all those costs?

- Which other resources or services will I need? E.g. Transcription, programs? training?

\subsection{Thesis Plan}

This is a very tentative indication of the proposed structure for your thesis. It is a good idea to show that you have thought about this, but do not spend much effort on this activity, since your thesis plan will most likely change many times as you develop your thesis. The plan should at least indicate the sequence of the proposed chapters for the whole thesis, and possibly how many words in each chapter. The total number of words for a Masters degree is about 60,000 $-70,000$ words. For a PhD this varies in the range 80,000 - 100, 000 (Dunleavy, 2003). There is great variance in these numbers and so you should discuss these with your supervisors. I use te metaphor of a plateau when advising my doctoral students on the word limits in each chapter. I refer to the first two or three chapters as climbing up the gentle slope of a plateau. So these chapters increase in word limits in the upward order of 7,00, 8,000, 9,000. The next three chapters sit on top of the plateau, so they each have an equal amount of words, say, 10,000, 10,000, and 10,000. The last three chapters descend from the plateau with a decreasing number of words such as, 9,000, 8,000, and 7000 . Assuming your doctoral thesis has nine chapters worded as per my plateau, you would end up with a thesis of 78,000 words. By the time you include the preliminary leading pages, plus references and appendices, you are likely to end up with a document about 100,000 words all up.

\subsection{List of References}

These must be compiled following the APA Styles manual (APA. 2012). Your reference list is not a bibliography. Therefore, you should include in it, only those publications you have cited in the different parts of your RP, not everything you have read.

\section{What Precautionary Measures Should You Take to Enhance Success of Your Research Proposal?}

In HDR studies the RP plays a very important part in getting one admitted into a university and subsequently in designing a research project that will lead to a successful authoring of a higher degree thesis (Dunleavy, 2003). In most universities, there is a big difference between your initial RP that you attach to your application for admission into a HDR and the final RP that you submit for your COC. The former, as said earlier, is a short (no more than 5 pages) document articulating exactly what you want to research into and how you intend to go about it. It is rather limited in breadth and depth. The latter, however, is a much more detailed and deeper analytical document that gets you to be accepted as a doctoral student or not. A weak initial RP could get you admitted but a weak final RP will not get you confirmed as a doctoral candidate. This can be cause for serious frustration and disappointment. One way to ensure that this does not happen is to work with your supervisors, and draw upon their considerable expertise to help you write a comprehensive RP.

It is important to identify a good supervisor. You can get some indication of this by doing some research on academics at the university where you intend to do your HDR studies. Focus your search on the area you want to research into. Read about your topic and see if one of the people who have published internationally about your proposed topic are at your chosen university Have a look at their publications, their research profiles and so on. If so, it is a good idea to contact them about your RP and seek their opinion, and whether they would be interested in supervising your research. This can facilitate the processing of your application.

Make sure your RP is on a topic that you are passionate about. If you are doing a $\mathrm{PhD}$ you will be working on it for 3-4 years full-time as the norm. This can be a very long time if you are working on something that does not really tickle your fancy. So, don't rush into finalizing the topic for your RP. Be flexible, and be prepared to switch topics, based on what you find out as you read more broadly and more deeply about your topic of interest.

Ensure that your RP demonstrates that you are familiar with how a RP is written, the language used, its structure and plan. Try to use your RP to convince your potential supervisors that you have the intellectual capacity to engage in HDR, you have a surprising question that is interesting, and you can prosecute it to find interesting, and significant answers.

Remember that the supervisors are there to help you. However, your thesis is your own argumentation, and entirely your own responsibility. So, as your prepare a RP to enable you to engage in HDR for it, give it your best effort, fall in 
love with it, feel proud about it, and make it the guide to your best academic product ever, which will enable you to contribute significantly to the knowledge pool in your field.

All the best with it.

\section{References}

APA. (2012). Publications manual of the American Psychological Association. $6^{\text {th }}$ edition. Washington, DC: American Psychological Association.

Bell, J. (1987). Doing your research project - A guide for First Time Researchers in Education and Social Science. Milton Keynes: Open University Press.

Beneke, R. R. \& Winterboer, R. (1973). Linear programming applications to agriculture. AMES, Iowa: The Iowa State University Press.

Burns, A. (2000). Introduction to research methods. $4^{\text {th }}$ Edition. Frenchs Forest: Pearson Education Australia.

Cohen, L. \& Manion, L. (1995). Research methods in education. London: Routeledge.

Cohen, L; \& Maldonado, A. (2007). Research methods in education. British Journal of Educational Studies, 55(4), pp. $146-158$.

Cooksey, R. \& McDonald, G. (2011). Surviving and thriving in postgraduate research, Prahran, VIC, Tilde University Press.

Cresswell J.W. \& Plano C. (2007). Designing and conducting mixed methods research. Thousand Oaks, CA: Sage.

Denzin, N.K. \& Lincoln, Y.S. (2000). Handbook of qualitative research. London: Sage.

Draper, N. R. \& Smith, H. (1966). Applied regression analysis. New York: John Wiley \& Sons.

Dunleavy, P. (2003). Authoring a PhD: How to plan, draft, write and finish a doctoral thesis or dissertation. New York: Palgrave Macmillan.

Glesne, C. (1998). Becoming qualitative researchers: An introduction. New York: Longman.

Glaser, B.G. \& Strauss, A.L. (1999). The discovery of grounded theory: Strategies for qualitative research. New York: Aldine de Gruyter.

Guba, E.G. 1992, The alternative paradigm. London, Sage.

Guba, E.G. \& Lincoln. Y.S. (1989). What is this constructivist paradigm anyway? In Fourth Generation Evaluation. London: Sage Publications, pp. 79-90.

Keeves J. (1997). Educational research methodology, and measurement, An International Handbook. $2^{\text {nd }}$ edition. London: Cambridge University Press.

Kivunja, C. D. (1978). The economics of cattle and beef marketing in Kenya. Frankfurt (Main): DLG-Verlag, (xii; 138pp).

Kivunja, C. D. (1984). The economics of the development of small farms in Africa, M. Agric. Econ. Thesis. Sydney: University of Sydney. (xvii, 268pp).

Kivunja, C. (2001). The establishment, leadership and improvement of educational organizations. Unpublished Master of Education Dissertation. Faculty of Education. UWS, Penrith Campus.

Kivunja, C. (2006). The structural and cultural dynamics of a multi-campus college: A case study inquiry of four multi-ampus colleges in New South Wales. PhD Dissertation. Penrith, University of Western Sydney. Available online: http://researchdirect.westernsydney.edu.au/islandora/object/uws:3644

Kivunja, C. \& Power, A. (2006). A New Dynamics Paradigm for Analysing Structural and Cultural Dynamics in an Educational Organisation, AARE 2006 International Education Research Conference: Engaging Pedagogies, Adelaide, Australia, 26th $\quad$ 30th 2006. http://www.aare.edu.au/publications-database.php/5112/A-new-dynamics-paradigm-for-analysing-structural-and -cultural-dynamics-in-an-educational-organisation

Kivunja, C. (2013). Embedding Digital Pedagogy in Pre-Service Higher Education, to Better Prepare Teachers for the Digital Generation, International Journal of Higher Education, 2(4), 131-142. http://dx.doi.org/10.5430/ijhe.v2n4p131

Kivunja, C. (2015a). Innovative Methodologies for $21^{\text {st }}$ Century Learning, Teaching and Assessment: A Convenience 
Sampling Investigation Into the Use of Social Media Technologies in Higher Education, International Journal of Higher Education, 4(2), 1 - 2. http://dx.doi.org/10.5430/ijhe.v4n2p1

Kivunja, C. (2015b). Exploring the Pedagogical Meaning and Implications of the 4Cs 'Super Skills' For The $21^{\text {st }}$ Century Through Bruner's 5E Lenses of Knowledge Construction to Improve Pedagogies Of The New Learning Paradigm. International Journal of Creative Education, 6(2), 1-19.

Kivunja, C. (2015c). Why students don't like assessment and how to change their perceptions in 21 st century pedagogies, Creative Education, 6(20), 2117-2126. http://dx.doi.org/10.4236/ce.2015.620215

Kivunja, C. (2015d). Teaching, learning and assessment: Steps towards creative practice. Melbourne, Vic: Oxford University Press.

Lancy, D. F. (1993). Qualitative research in education: An introduction to the Major Traditions. New York: Longman.

Le Compte, M. D.; Milroy, W. L. \& Preissle, J. eds. (1988). The handbook of qualitative research in education. New York: Academic Press.

Merriam, S. (2001). Qualitative research and case study applications in education. San Francisco: Jossey-Bass.

Neurath, O. (1973). The scientific conception of the world: The Vienna Circle. In M. Neurath \& R. Cohen (Eds.), Empiricism and sociology. Boston: Reidel. http://dx.doi.org/10.1007/978-94-010-2525-6

Patton, M.Q. 1988, Paradigms and pragmatism. In. D.M. Fetterman. (Ed.) Qualitative approaches to evaluation in education: the silent scientific revolution. (pp. 116-137), London: Praeger.

Render, B. \& Stair, R. M. (1994). Quantitative analysis for management. Boston: Allyn and Bacon.

Scott, D. \& Usher, R. (1996) (Eds.). Understanding educational research. London: Routledge.

Scott. D. \& Usher, R. (2004). Researching education: Data, methods, and theory in educational enquiry. New York: Continuum.

Schwab, D. P. (2005). Research methods for organizational studies, $2^{\text {nd }}$ edition. New Jersey: Lawrence Erlbaum Associates. 